\title{
Declared Pedagogical Values of Coaches at Hungarian Football Academies
}
Authors' contribution:
F) conception and design of the study
G) acquisition of data
H) analysis and interpretation of data
I) manuscript preparation
J) obtaining funding

\author{
Dániel Varga ${ }^{\mathrm{A}-\mathrm{E}}$, Gyöngyi Földesi ${ }^{\mathrm{A}, \mathrm{C}, \mathrm{D}}$, János Gombocz ${ }^{\mathrm{A}, \mathrm{C}}$ \\ University of Physical Education, Hungary, Budapest
}

ABSTRACT

\begin{abstract}
This paper is based on empirical research that was carried out in the total population of the coaches employed at Hungarian football academies $(\mathrm{N}=196)$. The main objectives of the investigation were to reveal the coaches' opinions about some major pedagogical views and to discover whether they realize their declared pedagogical values or not. The methods for collecting the data were a self-administered questionnaire, analysis of documents, and semi-structured interviews. The results are presented according to the following sub-topics: The content and the structure of the coaches' pedagogical values and the place of education in coaching effectiveness. Based on the findings, it is concluded that the disregard of pedagogical values can cause continuous harm to both the athletes and the coaches. The personality of young players suffering from educational and emotional neglect might develop in a one-sided manner. The effect of dysfunctional consequences with the coaches might prevent them from achieving their goals. In the worst case scenario, ignoring the young players' education can hinder the realization of the coaches' intended objectives and can result in unintended and adverse outcomes.

KEYWORDS forbidden sport doping, abolition of a ban of doping, usefulness and necessity of sport doping
\end{abstract}

\section{Introduction}

Participation in organized sport offers young athletes the opportunity to acquire and accumulate knowledge about social values, norms, and behavioral patterns in formal and informal ways. Beyond these, sport educates the athletes to effectively interact with their friends, helps them prevent and solve conflicts, and teaches them how to make proper decisions about their goals and behavior (Coakley 2009).

Coaches have two meaningful roles in these complex learning processes. As educators, they can have special pedagogical purposes and take responsibility for the development of their athletes' personalities. As socializing agents, they are significant persons in their athletes' lives with a strong social influence.

When examining coaches' pedagogical values, our starting point is socialization. The term has numerous definitions in the field of sociology, psychology, and pedagogy. From these, we adopted Gombocz's pedagogical concept for this study. According to Gombocz, socialization refers to the entire genesis of the personality; consequently, it also includes the effect of education. "Socialization produces and enriches the personality while being in interaction with the environment. In this way, the enrichment and versatility of an individual's activity can lead to the increasing of a personality's possibilities" (Gombocz 1997, p.87). 
Although sport as a social construction offers diverse socialization experiences, it is largely admitted that participating in sport is a key tool for socialization; its effect goes far beyond the learning process itself. It plays an outstanding role in the life of social communities, especially in family functioning; it creates the potential for social interactions between parents, their kids, coaches, and spectators (Dorsch \& Travis 2014). It can also have an impact on the relationships between the members of the family, the communication within the family, and even the behavior of the parents (Dorsch et al. 2015). Based on their empirical research, Holt et al. revealed that the positive effect of socialization through sport can be noticed in the athletes' communication and cooperation with different types of people (Holt et al. 2008, 2009).

Socialization is a broad concept; it refers to what happens every day in people's lives, including their sporting activities. Sport creates socializing situations, opportunities for social interactions through which the athletes learn not only sport-related social norms, values, beliefs, and habits dominant in their sporting group, but also acquire the elements of culture and special skills necessary for becoming a human and a functioning member of the society in which they were born.

Socialization through sport is not a one-way process, since not only sport can have an impact on the individuals, but also vice versa: the athletes can also influence others' socialization. For instance, the children and youngsters whose parents are physically active have a higher chance of participating in sport because of their parents' good example and their hypothetical support (Haycock et al. 2014).

Although in Gombocz's understanding socialization refers to the whole personality, he deals separately with the role of education in it. He emphasizes that the athletes do not differentiate between the socialization effect produced by education and other socializing tools, but since education is an intentional action is it worth paying special attention to it. Education plays a particular role in athletes' socialization. Both education and socialization involve learning, but education is planned while socialization is not necessarily planned. The complexity of the relationship between education and socialization can easily be seen in the coach's activity.

Socialization both in sport and through sport lasts throughout the whole life span. Therefore, whatever the athletes' ages are, coaches play an important role as socializing agents not only in the development of their sporting performances but also in the development of their character. However, because childhood and youth are outstanding periods of socialization, the responsibility of coaches training children and adolescents and at the same time transmitting social norms, values, and behavioral patterns to them is exceptional. This statement is even truer for coaches working with elite pre-teen and teenage athletes.

Since football became a big business, the number of young people who are training with the aim of entering the world of professional football is growing. Many leading sport clubs offer educational and technical programs to children and adolescents worldwide with the aim of preparing them to play in their first team in the future. The overall objective of the activity of coaches employed even by such centers of excellence is to get the best results their team is capable of. Hence, it is extremely important to raise these coaches' consciousness about their singular role both in socialization and education.

In order to make the coaches aware of their particular liability for their young athletes, it is essential to know what their major pedagogical values are and what importance they ascribe to them. The Hungarian and international literature is relatively scarce about giving the reports of studies focusing on these problems. To this end, we have recently performed empirical research on this topic.

\section{Objectives}

Based on the partial results of our empirical research, the objectives of this paper are:

- to present what the coaches dealing with the children and adolescents recruited to become elite football players think about some major pedagogical views;

- to find out whether the coaches realize their declared pedagogical values;

- to see how the methodological experiences of the pilot study carried out previously could help in using more effective methods in the present research. 


\section{Football academies}

Football academies can be found in many countries all over the world. In England, the Centres of Excellence are considered to be predecessors of the football academies, while in Spain the name "Cantera" (meaning quarry) was used.

In Hungary, the first football academy was founded in 2001, and then at the end of the 2000s several elite football clubs established their own recruitment centers. The objectives of such academies are very similar in different corners of the world. Namely, they are to collect and educate talented children and train them at a very high level. However, these academies are rather different in their functioning and their organizational structure, as well as in the housing, teaching, and training conditions that they offer their young players.

Besides the academies connected to sport clubs, several national football associations founded academies. Moreover, there are football academies in some developing countries that were established either by former elite football players or world-famous sport clubs, which also gave birth to such academies in order to increase the chance of finding gifted athletes.

Academies offer various housing opportunities to their athletes; they can stay either in dormitories in a boarding system, or with families living close to the sport clubs. The top Hungarian football academies typically function in the boarding system. The players study in public schools in various forms of cooperation with the academies. The infrastructure for teaching-learning is provided either by the academies or by the cooperating school. Accordingly, sometimes the schools relocate education to an academy; sometimes the school transforms the pedagogical program of the relevant classes to the needs and special demands of studentathletes at the academy. The Hungarian Football Federation adopted the criteria defined by the European Football Association (UEFA) in order to create a uniform qualification system. As a part of this procedure, the status of individual academies is evaluated on the basis of the conditions they offer related to the athletes' housing, catering, learning, and training (MLSZ 2012).

At the football academies, the young athletes learn how to live together in a community, how to adapt themselves to each other, and how to cooperate with each other. Beyond these objectives, another objective of the academies is to develop the players' sense of identity with their team in order to be loyal to their team, which also functions as a strong socializing agent. It affects the team members' struggle to reach collective aims and to learn how to take responsibility for each other.

Football academies ensure the scientific and infrastructural conditions in accordance with the athletes' ages. They pay attention to the development of the players' individual skills, such as self-discipline, monotony tolerance, failure tolerance, and even health consciousness.

\section{Methods}

\section{The examined population}

This research was carried out among the total population of coaches working at the 15 prioritized Hungarian football academies. The list consisted of the names of 217 coaches, 196 of which participated in the investigation on a voluntary basis. Roughly half of the missing 19 coaches were not willing to take part in the research; the other half just missed the opportunity to be present at the data collection. On the whole, only one academy is underrepresented in the examined population; from all the others, one or two coaches were absent when the process of gathering the data took place.

\section{Characteristics of the population}

The overwhelming majority of the examined population consisted of males (almost 98\%); therefore, gender distribution was inapplicable.

Two-thirds of the coaches were between the ages of 30 and 50. The remaining one-third was divided, broadly speaking, equally between the younger (under 30 years old) and the older (aged 50 and above) coaches.

Regarding the coaches' professional qualifications, almost all of the coaches (98.5\%) were certified through the courses of the UEFA or the HFA, which empowered them to work as football coaches. In addition, $20.9 \%$ of them graduated from universities and colleges, $26.5 \%$ of them were certified at the upper secondary 
school level, and $10.2 \%$ were certified at a basic level. A total of $42.4 \%$ of the coaches did not attend educational institutions for getting a degree/certification in coaching.

\section{Data collection}

The basic method for collecting the data was a self-administered questionnaire conducted in group settings in each academy in the presence of the leader of this investigation. This means that the coaches of the given academy, while sitting together in groups, answered the questionnaire individually and anonymously. The structure of the questionnaire was similar to the one that was used in the pilot study, but several questions were modified based on the first-hand experience gained there. One of the major changes was that, contrary to the pilot study, in more cases than not, the coaches had to choose only one of the suggested alternatives and hierarchize them directly. Moreover, more scales were developed asking the coaches to respond concerning how much they agreed or disagreed with a series of statements. The modification of the questions proved to be functional; the answers seemed to express the coaches' views more sensibly.

In addition, two qualitative methods were employed for collecting data: the analysis of documents and semi-structured interviews. The report and the documentation of a comprehensive audit of all prioritized Hungarian football academies implemented in 2016 served as adequate and rich material for analysis. Semistructured interviews were made with former head coaches and other football experts $(\mathrm{N}=6)$. The guideline of the interviews focused on the realization of the coaches' declared pedagogical values and on the reasons for the inconsistency between their declared and realized values.

\section{Data processing}

Data were processed using the SPSS 22 program. Descriptive statistics were obtained to describe and compare the coaches' pedagogical views. Besides this, the Chi-square test was used to determine whether there was a significant relationship between some selected categorical variables.

\section{Results}

\section{The content and structure of the coaches' pedagogical values}

The starting point was to clarify what the concept of education means to the coaches in the examined population. Ranking the characteristics of the term, the coaches put the significance of the personal example in first place. It was followed by the importance of teaching respect for the game, the team, and the opponents. In third place, the coaches chose the value of the development of the players' personalities. Although the means of the coaches' answers are close to each other throughout the ranking, except for one item (transmitting personal experiences), the results of the interviews warn us to have reservations concerning their grading, at least as far as the realization of their declared values is concerned. It is more plausible that the coaches do not attach great importance to the transmission of basic social norms and values; they ranked this characteristic in the second-to-last place (Table 1).

Table 1. The meaning of education for coaches $(\mathrm{N}=193)$

\begin{tabular}{|c|c|c|c|}
\hline Characteristics of the concept & Rank & Mean & Std. dev. \\
\hline Providing a personal example & 1. & 4.60 & 0.62 \\
\hline Teaching respect for the game, the team, and the opponent & 2. & 4.58 & 0.68 \\
\hline Developing the players' personalities & 3. & 4.46 & 0.80 \\
\hline Identifying talents and nurturing them & 4. & 4.45 & 0.79 \\
\hline Teaching social norms and values & 5. & 4.44 & 0.80 \\
\hline Transmitting experiences & 6. & 3.97 & 0.92 \\
\hline
\end{tabular}


First, we got the distinct impression that many coaches tried to answer the questions in a manner that they guessed would match our expectations. A deeper analysis showed that even if this was the case, the answers might be misleading, since several coaches lacked sufficient pedagogical knowledge for that. For instance, a coach with a university degree said the following when he was interviewed: "If you refer to pedagogical methods, I never learn new ones. I always acted entirely intuitively in this area, I hardly studied any pedagogy."

In direct speech, the majority of the examined football coaches admitted the relevance of pedagogical knowledge in their work. However, in an indirect context, it was unambiguous that they underestimated its weight. For example, when they presented their opinion on the influential pedagogical tools, they put theoretical pedagogical knowledge in the last place in the ranking (Table 2).

Table 2. Football coaches' opinions about the influential tools of education $(\mathrm{N}=194)$

\begin{tabular}{lcccc}
\multicolumn{1}{r}{ Tools of education } & Rank & Mean & Std. dev. \\
\hline Good examples & 1. & 4.64 & 0.62 \\
\hline Coherence & 2. & 4.63 & 0.63 \\
\hline Coaches' personalities & 3. & 4.60 & 0.64 \\
\hline Professional competence & 4. & 4.53 & 0.77 \\
\hline Consciousness & 5. & 4.46 & 0.64 \\
\hline Purposeful and systematic work & $6-7$. & 4.43 & 0.71 \\
\hline Concern, attention & $6-7$. & 4.43 & 0.68 \\
\hline Patience & 8. & 4.21 & 0.74 \\
\hline Love & 9. & 3.99 & 0.89 \\
\hline Theoretical pedagogical knowledge & 10. & 3.93 & 0.97 \\
\hline
\end{tabular}

Source: Own study.

Table 2 also shows that the second-to-last item in the coaches' ranking is "love." In other words, they are not particularly motivated to develop emotional ties with their players. They do not realize that the lack of emotional connection between themselves and their young footballers might have a serious negative effect; it can even contribute to some players dropping out early (Varga 2017a).

Largely similar to the findings of our previous research (Varga 2017b), at the top of the ranking you can find good examples, coherence, the coaches' professional knowledge, and their personalities; while patience, concern, attention, and systematic work do not seem to be appreciated by the coaches these items occupy the last places in their ranking. The analysis of the data also shows that they underestimate the potential consequences of the missing pedagogical knowledge and the lack of emotional ties regardless of their age, the length of their coaching career, and whether or not they had experience abroad. We could not find any significant correlation between the order in the ranking and the above-mentioned individual variables.

\section{The place of education in coaching effectiveness}

In spite of their deficient pedagogical knowledge, the examined football coaches are of the opinion that education is possible in football; more than $90 \%$ of them gave this statement a mark of four or five on a fivepoint scale. At the same time, only one-fifth of them believe that Hungarian football coaches effectively develop their players' personalities, while three-quarters suppose that present-day Hungarian coaches work moderately in this field. They consider themselves to be exceptions; more than $90 \%$ of them are convinced that they positively contribute to the personal development of their players. 
However, other findings helped clarify that when coaches were talking about the personal development of their athletes, the majority of them meant the advancement of their young players' sporting skills rather than the improvement of their personality traits. According to the coaches, the impact of their "educational" activity resulted first of all in a more positive attitude towards their training load, cooperation with their coach, and life in general (Table 3).

Table 3. Results related to the coaches' educational activity $(\mathrm{N}=195)$

\begin{tabular}{llll}
\hline Results of the coaches' educational activity & Rank & Mean & Std. dev. \\
\hline More positive attitude towards training loads & 1. & 4.39 & 0.68 \\
\hline Better cooperation with the coach & 2. & 4.28 & 0.60 \\
\hline More positive attitude towards life & 3. & 4.28 & 0.71 \\
\hline Better relationships with other players & 4. & 4.17 & 0.78 \\
\hline The players become more polite & 5. & 3.99 & 3.90 \\
\hline The players stand for a healthier lifestyle & 6. & 3.84 & 0.73 \\
\hline The players become more virtuous & 7. & 3.83 & 0.79 \\
\hline The players became more knowledgeable & 8. & 3.30 & 0.79 \\
\hline The players become more cultivated & 9. & 32 \\
\hline
\end{tabular}

Source: Own study.

Table 3 also shows that the coaches might have made endeavors to improve the relationships between their players. Nevertheless, the findings also reveal indirectly that they made less of an effort to increase the level of their players' general culture, knowledge, morals, and health. When evaluating the outcome of their own activity, the coaches gave the lowest marks to these items, less than four on a five-point scale. What is even more important, contrary to the pilot study, they ranked these items themselves from the most important to the least important.

The above findings are very much in line with the coaches' preferences related to their educational activity (Table 4) and with their opinions about the importance of different elements of their educational practice (Table 5).

Table 4. The coaches' preferences when educating their players

\begin{tabular}{llll}
\multicolumn{1}{c}{ The coaches' preferences } & Rank & Means & Std. dev. \\
\hline To transmit professional knowledge & 1. & 4.71 & 0.62 \\
\hline To solve the team's problems & 2. & 4.49 & 0.62 \\
\hline To ensure order and discipline & 3. & 4.47 & 0.71 \\
\hline To solve individual problems & 4. & 4.35 & 0.69 \\
\hline To manage conflicts & 5. & 4.13 & 0.87 \\
\hline To transmit culture & 6. & 3.70 & 0.82 \\
\hline To plan education & 7. & 3.55 & 0.90 \\
\hline
\end{tabular}

Source: Own study. 
Table 5. The coaches' opinions on the importance of different elements of their educational practice

\begin{tabular}{llll}
\multicolumn{1}{c}{ Elements of educational practice } & Rank & Means & Std. dev. \\
\hline The coach's personality & 1. & 4.56 & 0.58 \\
\hline The coach's targeted and systematic work & 2. & 4.50 & 0.66 \\
\hline The coach's pedagogical sense & 3. & 4.39 & 0.64 \\
\hline The coach's consciousness & 4. & 4.25 & 0.68 \\
\hline The coach's theoretical knowledge in pedagogy & 5. & 3.63 & 0.79 \\
\hline
\end{tabular}

Source: Own study.

The findings in Table 4 demonstrate how much the coaches misjudge the necessity of planning pedagogical work. Even in this context, they rank the transmission of professional knowledge the highest, while transmitting cultural information is in second-to-last place, followed only by the planning of education. From the data in Table 5, it seems that the coaches do not really appreciate theoretical knowledge in pedagogy and conscious pedagogical implication in their professional activity. The interviews were further proof of the assumptions suggested by the data in the tables and the misinterpretation and simplification of the term "education." An excellent football expert formulated his views about this question in the following way

"I have little doubt that education for the coaches is a marginal issue. One can even understand that this aspect of their work is beside the point. After all, they are not paid for teaching good manners to their players."

\section{Discussion and Conclusion}

There are different views about coaching effectiveness; its essence still must be agreed upon. Some concepts put the athlete-coach relationship at its heart (Jowet 2017). Others emphasize the necessity to measure it in objective ways (Carter 2006; Tooth et al. 2013). A relevant study focuses on the coaches' knowledge, stating that it makes coaching effective and tries to measure coaching knowledge with the help of a special survey (Jesse et al. 2014). From the perspective of our research, the relevant issue is that in principle, as a rule, pedagogy is considered to be a part of the coaches' knowledge; it is included in their professional, sportspecific knowledge (Mallett \& Côté 2009).

The findings of our research suggest that, except for some committed and passionate Hungarian coaches, this approach to professional knowledge has not yet been adopted in the everyday practice of most examined coaches.

Pedagogical values play little importance in their value system, if any. In their declaration, many of them speak about the significance of respecting and adopting pedagogy, but when they give an account of their own practice, the situation looks different. The overall objective of winning, on the basis of which their coaching effectiveness is valued, might be the main reason for the coaches paying negligent attention to the pedagogical aspects of their activity. The disregard of pedagogical values can be harmful to both the athletes and the coaches. The personalities of the young players suffering from educational and emotional neglect might develop in a one-sided manner, which may lead either to identification with the principle of "winning at all costs" or, at the other extreme, to their early dropout and their short-lived football careers. The dysfunctional consequences may affect the coaches as well. In the worst case scenario, ignoring the young players' education can hinder the realization of the coaches' intended objectives and result in unintended and adverse outcomes. In the short term, they can be successful. However, in the long term, instead of achieving the best possible performance with their football team, they might fail in their attempt to promote a winning spirit and cause disappointment and frustration concerning their broad and narrow environments. The precondition for the long-term success and stability of any children's/junior football team seems to be the coaches' approach to their professional activities in all their complexity. 
Finally, it is worth mentioning that, based on the methodological experience gained from our pilot study, the methods that were used to carry out this research were successfully improved. This methodological development contributed to the credibility of the research data and the trustworthy interpretation of the findings.

\section{REFERENCES}

Carter, A. (2006). Practical Methods for Evaluating Coaching. Brighton: Institute for Employment Studies. University of Sussex.

Coakley, J. (2009). Sport in Society: Issues and Controversies. New York: McGraw Hill.

Dorsch, T.E. (2014). Parent sport socialization, goals and verbal sideline behavior, and support and pressure in organized youth sport. Dissertation Abstracts International: Section B: The Sciences and Engineering, 75(4-B)(E).

Dorsch, T.E., Smith, A.L. \& McDonough, M.H. (2015). Early socialization of parents through organized youth sport. Sport, Exercise, and Performance Psychology, 4(1), 3-18.

Gombocz, J. (1997). A sportoló szocializációja és nevelése [The athlete's socialization and his/her education]. Kalokagathia, 35(1-2), 83-94.

Haycock, D. \& Smith, A. (2014). A family affair? Exploring the influence of childhood sport socialisation on young adults' leisure-sport careers in north-west England. Leisure Studies, 33(3), 285-304.

Holt, N.L., Tink, L.N., Mandigo, J.L., \& Fox, K.R. (2008). Do youth learn life skills through their involvement in high school sport? A case study. Canadian Journal of Education, 31(2), 281-304.

Holt, N.L., Tamminen, K.A., Tink, L.N. \& Black, D.E. (2009). An interpretive analysis of life skills associated with sport participation. Qualitative Research in Sport and Exercise, 1, 160-175.

Jesse, D., Sutton, J. \& Linick, M. (2014). Analysis of the Coaching Knowledge Survey: Evidence for Validation and Next Steps. Unpublished manuscript, Examining Mathematics Coaching Project. Denver, Colorado: RMC Research Corporation.

Jowet, S. (2017). Coaching effectiveness: The coach-athlete relationship at its heart. Current Opinion in Psychology, 16, 154-158.

Magyar Labdarúgó-szövetség (MLSZ) (2012). Tájékoztató a labdarúgó akadémiák licencminősitési eljárásáról [Handout about the proceedings of the license qualification at football academies]. Budapest: MLSZ.

Mallett, C. \& Côté, J. (2009). What is Coaching Effectiveness? Retrieved January 16, 2018, from http://www.globalcoacheshouse.net/assets/files/Presentations/What_is_coaching_effectiveness.pdf

Tooth, J.A., Nielsen, S. \& Armstrong, H. (2013). Coaching effectiveness survey instruments: Taking stock of measuring the immeasurable. Coaching: An International Journal of Theory, Research and Practice, 6(2), pp. 137-151.

Varga, D. (2017a). Képben a gyermekkép: labdarúgó edzők nézetei a mester és utánpótláskorú tanítványai kapcsolatáról [Children's image in the picture: Football coaches' beliefs about the relationship between the master and his 'joueur espoir"]. Magyar Sporttudományi Szemle, 18(3), 46-51.

Varga, D. (2017b). Coaches: Pedagogues of sport? Methodological attempt to study the pedagogical beliefs of Hungarian football coaches. Physical Culture and Sport. Studies and Research, 76(4), 31-42.

AUTHOR'S ADDRESS: Daniel Varga

University of Physical Education in Budapest

Alkotas u. 44, Budapest

1123 Hungary

E-mail: varga.daniel@tf.hu

Received: 30 January 2018; Accepted: 28 Febraury 2018 